\title{
The Effect of M-Health-Based Core Stability Exercise Combined with Self-Compassion Training for Patients with Nonspecific Chronic Low Back Pain: A Randomized Controlled Pilot Study
}

\author{
Fuming Zheng • Yiyi Zheng · Shufeng Liu • Jiajia Yang • Weihui Xiao • \\ Wenwu Xiao · Lichang Chen · Wanting Yang · Shanshan Zhang • Qiuhua Yu • \\ Zengming Hao · Yuyin Wang · Chuhuai Wang
}

Received: November 24, 2021 / Accepted: January 19, 2022 / Published online: February 8, 2022

(c) The Author(s) 2022

\section{ABSTRACT}

Introduction: Nonspecific chronic low back pain (NCLBP) is a leading contributor to disease burden worldwide, and the management of NCLBP has always been a problem. This study is designed to explore the feasibility and efficacy of m-health-based core stability exercise (CSE) combined with self-compassion training (SCT) and compare it with m-health-based CSE alone for the management of NCLBP.

Methods: This study is a pilot, patient-blinded randomized controlled trial. Participants with NCLBP were randomized into an intervention group and a control group. All the participants received $m$-health-based CSE, but those in the intervention group also received SCT before CSE.

Fuming Zheng and Yiyi Zheng are co-first authors.

F. Zheng · Y. Zheng · S. Liu · J. Yang - W. Xiao ·

S. Zhang · Q. Yu $\cdot$ Z. Hao $\cdot$ C. Wang $(\bowtie)$

Department of Rehabilitation Medicine, The First

Affiliated Hospital, Sun Yat-Sen University,

Guangzhou 510080, China

e-mail: wangchuh@mail.sysu.edu.cn

W. Xiao $\cdot$ W. Yang $\cdot$ Y. Wang ( $₫)$

Department of Psychology, Sun Yat-Sen University,

Guangzhou 510006, China

e-mail: wangyuy2@mail.sysu.edu.cn

\section{Chen}

Department of Medical Statistics and Epidemiology, School of Public Health, Sun Yat-Sen University, Guangzhou 510080, China
The intervention took place weekly on Saturday or Sunday for 4 weeks in total. Patients selfassessed their outcomes by filling out electronic questionnaires at 4 and 16 weeks after the start of the study. The primary outcome metrics for these questionnaires were back pain disability (based on the Roland-Morris Disability Questionnaire, RMDQ) and Pain intensity (Numeric Rating Scale, NRS; current pain, worst pain, average pain). The secondary outcome metrics were anxiety (GAD7,7-item Generalized Anxiety Disorder scale), Depression Symptoms (PHQ-9,Patient Health Questionnaire-9), pain catastrophizing (PCS, Pain Catastrophizing Scale) and Self-efficiency (PSEQ, Pain Self-Efficiency Questionnaire).

Results: A total of 37 patients comprising 28 (75.7\%) females completed the study, with 19 patients in the intervention group and 18 in the control group. The mean (SD) patient age was 35.2 (11.1) years. For all primary outcomes, although there were no significant differences between groups, we found that participants in the intervention group improved function and pain earlier. The RMDQ score changed by - 1.771 points $(95 \% \mathrm{CI}-3.768$ to 0.227$)$ from baseline to 4 weeks in the control group and by -4.822 points $(95 \% \mathrm{CI}-6.752$ to -2.892$)$ in the intervention group (difference between groups, -3.052 [95\% CI -5.836 to -0.267$]$ ). Also, the RMDQ score changed by -3.328 points ( $95 \%$ CI -5.252 to -1.403$)$ from baseline to 16 weeks in the control group and by -5.124 points $(95 \% \mathrm{CI}-7.014$ to -3.233$)$ in 
the intervention group (difference between groups -1.796 [95\% CI -4.501 to 0.909$]$ ). A similar pattern was found in the NRS scores. For secondary outcomes, the intervention group was superior to the control group in for GAD-7 (intervention difference from CSE along at week $16,-2.156$ [95\% CI -4.434 to -0.122 ; $P$ value for group effect was 0.030]). At the end of treatment, the improvement in PCS in the intervention group was significant (difference in PCS score at week $4,-6.718$ [95\% CI -11.872 to -1.564$])$. We also found significant changes in PCS in the control group $(-6.326$ [95\% CI, -11.250 to -1.401$]$ ) at the 16-week followup. As for PSEQ, there were no apparent differences between the two groups. There were no adverse events relented to study participation.

Conclusions: The pilot study is feasible to deliver, and our results indicate that participants in the group of m-health-based CSE combined with SCT may experience faster relief from pain intensity and back disability than those in the group of m-health-based CSE alone. Trial Registration: ChiCTR2100042810.

\section{PLAIN LANGUAGE SUMMARY}

The impact of chronic low back pain on people's life quality and social economy is increasing year by year. Helping patients self-manage low back pain through a biological-psycho-social model seems to be an effective management approach, but the lack of connectivity between disciplines limits the development of multidisciplinary collaboration. Mindfulness-related therapy (self-compassion training) has been proven to be effective in chronic pain, and exercise therapy is widely used in rehabilitation medicine. In this study, these two programs were combined. We also used mobile health technology in the study, which brings a lot of convenience for research. The results of the study showed that the efficacy of the combined group seemed to be more obvious and worthy of further study.
Keywords: Nonspecific chronic low back pain; Core stability exercise; Self-compassion training; Mobile health

\section{Key Summary Points}

Why carry out this study?

Nonspecific chronic low back pain (NCLBP) is a major public health and global socioeconomic burden with a variety of symptoms. So far, the treatment and management still face enormous challenges.

We hypothesized that m-health-based core stability exercise (CSE) combined with self-compassion training (SCT) would be an effective form to help patients alleviate their back pain and it requires clinical validation.

The study aimed to assess the feasibility of proceeding to future definitive randomized controlled trials.

\section{What was learned from the study?}

With the addition of self-compassion, more patients with NCLBP may experience faster relief from pain intensity and back disability.

The pilot study is feasible and warrants a larger study to provide high-quality evidence.

\section{INTRODUCTION}

Nonspecific chronic low back pain (NCLBP) is used when the pathoanatomical cause of the pain cannot be determined [1], and it is an affliction suffered by many worldwide that can have a significant impact on both the mind and body and quality of life in general [2]. Although there is a vast range of therapies to treat NCLBP, the social burden associated with NCLBP has been increasing [3]. 
The condition is complex, with multiple contributors to both pain and associated disabilities, including psychological factors, social factors, biophysical factors, comorbidities, and pain-processing mechanisms [4]. Guidelines for the management of NCLBP recommend noninvasive nonpharmacologic methods [5], such as exercise, psychological therapy, spinal manipulation, low-level laser therapy, massage, mindfulness-based stress reduction (MBSR), yoga, acupuncture, and multidisciplinary biopsychosocial rehabilitation (MBR) [6]. When combined with physical, psychological, social, and/or work-related components, MBR has been shown to be more effective than usual care and physical treatments in decreasing pain and disability in people with NCLBP [7]. At present, the research on psychological intervention in NCLBP mainly concentrates on developed countries [6], and there is still a lack of relevant research in developing countries.

The lumbar multifidus (LM) and transversus abdominis (TrA) are deep stabilizing spinal muscles that play crucial roles in the lumbar spine [8]. Studies have reported that there is significant atrophy, fat infiltration, and/or decrease in activation of the TrA and LM muscles in individuals with NCLBP $[9,10]$. Core stability exercises (CSE) can increase the activation of LM and TrA and have been proven useful for treating NCLBP [11]. So CSE has become the first recommended treatment for NCLBP by Chinese therapists. However, patients with NCLBP have been observed to exhibit poor adherence to exercise training without supervision, leading to poor efficiency [12]. Exercise based on mobile-health (mhealth) is a novel approach to delivery of the exercise training using personal mobile phones [13] that grew rapidly during the COVID-19 outbreak [14]. It can bring convenient and inexpensive care to patients [15]. Our preliminary study about m-health-based exercise shows that this method is effective for NCLBP but the effect size is not very high. Relevant trials have suggested that psychotherapies such as cognitive behavioral treatment (CBT) [16, 17], mindfulness-based stress reduction (MBSR) [18] and self-compassion training (SCT) $[19,20]$ can be effective treatment options for patients with
NCLBP. Among them, self-compassion is a state of mind that treats oneself compassionately in the face of pain and stress. It includes three components: mindfulness, self-kindness, and common humanity [21]. Some studies have found that self-compassion is an important protective factor for mental health and plays a role in the treatment of chronic pain $[22,23]$. Importantly, SCT has been shown to be able to increase the practice of health-promoting behaviors [24, 25]. It still remains unknown if the SCT can enhance the effect of CSE. To our knowledge, there is no research reported about it. Furthermore, most of the studies on the treatment of chronic low back pain by exercise therapy are based on the perspective of biomechanics only $[26,27]$, but not combined with psychotherapy. Theoretically, the combination of psychotherapy and exercise therapy would have better therapeutic effects, but relevant evidence is lacking.

Based on the above-described gaps in research, we designed this pilot study to explore the efficacy and feasibility of m-health-based CSE combined with SCT in order to compare it to m-health-based CSE alone for the management of NCLBP. We hypothesized that m-health-based CSE combined with SCT would be a more effective form of treatment after a follow-up period of 16 weeks.

\section{METHODS}

\section{Study Design and Settings}

We designed this trial as a randomized, controlled, and patient-blinded trial with two parallel groups: intervention and control. Randomization was performed as block randomization with a 1:1 allocation. The control group received m-health-based CSE only while the intervention group received a combination of CSE and SCT. Participants were then asked to complete a follow-up assessment at 4 weeks (post-treatment), and 16 weeks (the primary end point) after randomization. This study was performed in accordance with the Helsinki Declaration of 1964 and its later amendments, and it has been approved and supervised by the 
Ethics Committee of the First Affiliated Hospital of Sun Yat-Sen University. The approval number is [2021]079. Written informed consent was obtained from all participants included in the study. The study has been prospectively registered with the Chinese Clinical Trials Registry, Number: ChiCTR2100042810 (1/21/2021). To maintain the quality of reporting, we used the CONSORT 2010 Statement: Extension to Randomized Pilot and Feasibility Trials guideline checklist [28].

\section{Participants}

We recruited the participants from April 10, 2021 to July 15, 2021 via a social network and an advertisement posted at our clinic. To be eligible for recruitment, participants must have been aged 18-60 years, had back pain that had persisted for at least 12 weeks, and been willing to participate in the study. Potential patients for the trial were excluded if any of the following criteria were met: First, patients were excluded if there were clear "red flag" signs (unilateral leg pain and numbness consistent with nerve distribution, intermittent claudication, weight loss without obvious cause, nighttime pain, trauma, etc.) that indicate that their back pain was not nonspecific. Next, patients were excluded if they were unable to participate in therapy on weekend. Patients were also excluded if they had a score $<4$ on the RMDQ. We also excluded patients who had practiced meditation regularly (weekly) in the previous 3 months and patients who had participated in courses relating to CSE in the previous 3 months. After that, we excluded patients who had conditions that may be uncontrolled for self-compassion meditation (psychosis, major depression or anxiety, current self-harm, or suicidal ideation). Finally, we excluded patients who were unable to complete Chinese-language questionnaires independently. The principal investigator (ZFM) introduced the trial to potential participants and determined whether to include them through detailed physical examination.

\section{Interventions}

We conducted two parallel interventions in May and August 2021. In each intervention, the participants was randomized into the intervention and control groups (ten participants in each group). The intervention group received m-health-based SCT plus CSE, and the control group received $\mathrm{m}$-health-based CSE only. The treatment was divided into two parts: face-toface intervention and self-help exercise at home. The face-to-face intervention took place in Rehabilitation Clinic of the First Affiliated Hospital of Sun Yat-Sen University on Saturday or Sunday for 4 weeks in total because most of the NCLBP patients need to work on the weekdays. The self-help exercise was provided by the Anyoukang (AUK) exercise training system, which would provide daily exercise reminders and video guidance via WeChat (Fig. 1).

\section{Core Stability Exercise (CSE)}

The formulation of exercise prescriptions was developed on the basis of our treatment experience and referred to other studies [26, 29]. The CSE was divided into two parts: face-to-face guidance $(1.5 \mathrm{~h}$ per session, once a week for 4 weeks) and self-help exercise at home (30-40 min per session, at least three times a week). Participants were also required to complete an electronic daily training diary after each training session. The rehabilitation exercises included spinal mobilization exercises (involving exercises aimed at relaxing the tense muscles of low back), and strengthening exercises (involving exercises aimed at developing motor control of the spine and pelvis) (Table 1). Two professional physiotherapists with at least 5 years of experience led the program.

\section{Self-Compassion Training (SCT)}

SCT was adapted from our previous study [30] with some minor modifications based on the characteristics of NCLBP. The intervention consisted of four face-to-face group interventions ( $2 \mathrm{~h}$ per session) and family exercises. During the intervention, group leaders 


\section{Physical exercise}

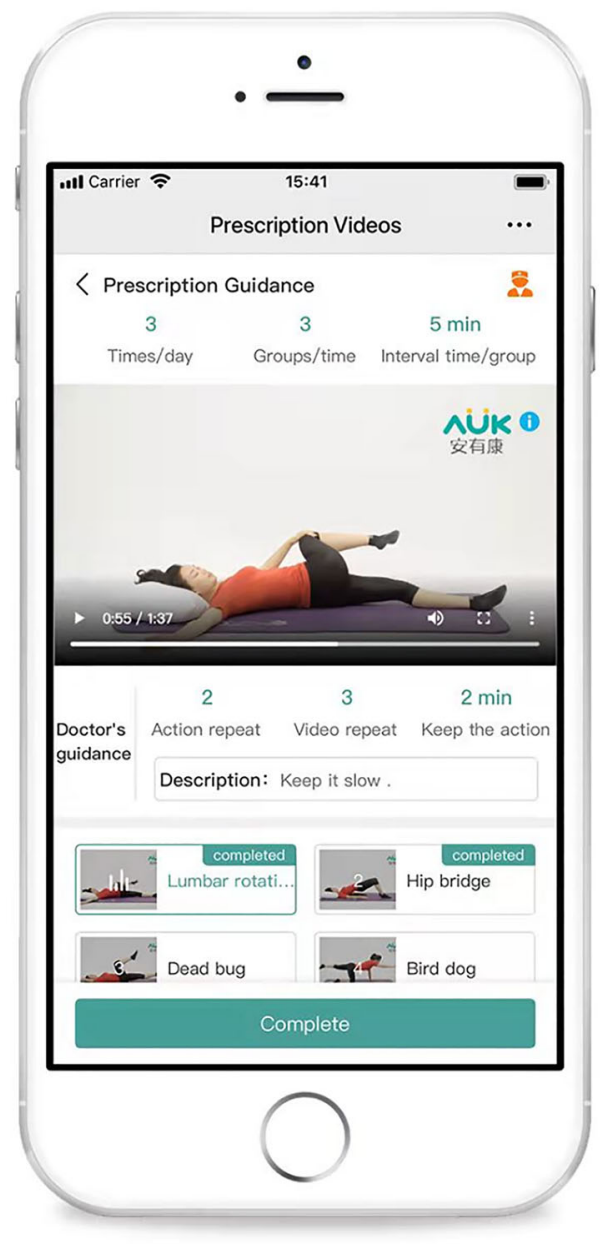

Fig. 1 Examples of the AUK exercise system

introduced information about self-compassion and guided participants through a series of practices, and participants were encouraged to do home practices following the guidelines provided by the group leaders. Psycho-education about self-compassion was provided in the first session and a few practices to improve participants' awareness of stress (for example, observing body sensations under NCLBP) were presented. The second session sought to advance participants' understanding of selfcompassion using exercises that focused on the experience practices (for example, affectionate breathing meditation). The third session focused on guiding participants to meet stress with self-compassion (for example, loving-

\section{Reminder exercise}

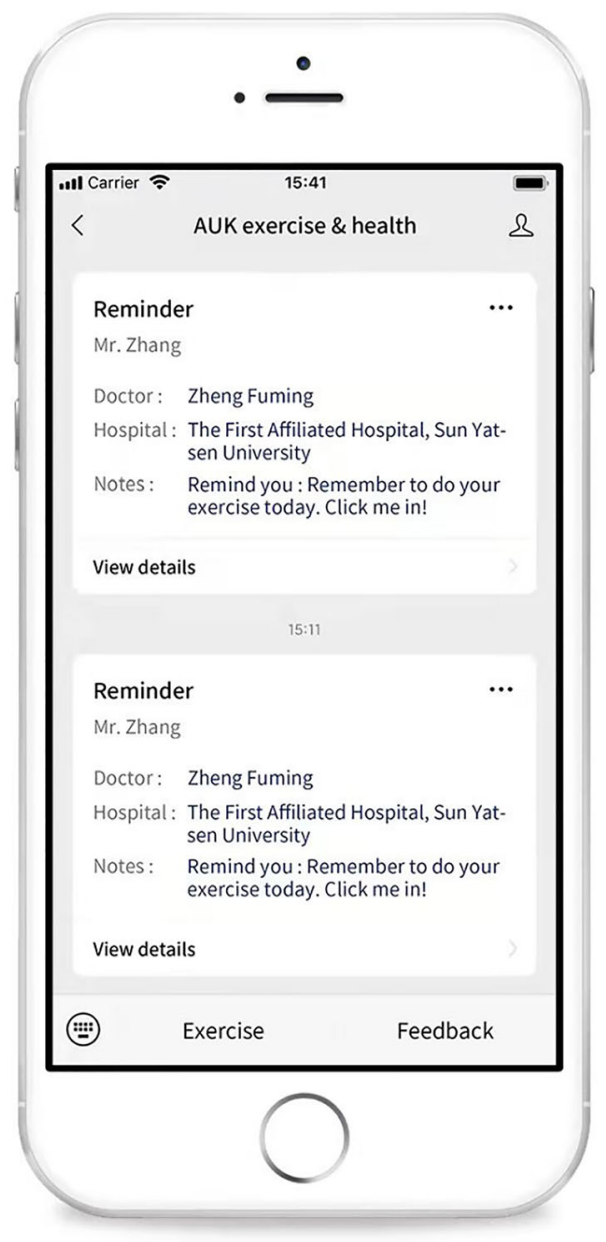

kindness meditation for ourselves). Finally, in the last session, participants discussed and reviewed their experience during the intervention with the group and made plans for future self-compassion practice (Table 1). The SCT was co-led by two graduate students in counseling psychology who had an adequate theoretical understanding of self-compassion and practiced mindfulness and self-compassion themselves. The whole intervention process was supervised by a counseling psychologist.

\section{Outcomes}

Participants completed outcomes at baseline, 4-weeks follow-up (post-treatment), and 
Table 1 Content of core stability exercise and self-compassion training class sessions

\begin{tabular}{|c|c|c|c|c|}
\hline \multirow[t]{2}{*}{ Session } & \multicolumn{2}{|c|}{ Core stability exercise } & \multicolumn{2}{|c|}{ Self-compassion training } \\
\hline & Theme & $\begin{array}{l}\text { Content } \\
\text { (times*duration) }\end{array}$ & Theme & Content \\
\hline 1 & $\begin{array}{l}\text { Spinal } \\
\text { mobilization } \\
\text { exercises }\end{array}$ & $\begin{array}{l}\text { Rolling spine } \\
\text { exercise }\left(1^{*} 60 \mathrm{~s}\right) \\
\text { Lumbar rotation } \\
\left(4^{*} 15 \mathrm{~s}\right) \\
\text { Lumbar extension } \\
\left(2^{*} 15 \mathrm{~s}\right) \\
\text { Cat stretch } \\
\left(2^{*} 15 \mathrm{~s}\right)\end{array}$ & $\begin{array}{c}\text { Back to body } \\
\text { sensations }\end{array}$ & $\begin{array}{l}\text { Self-introduction } \\
\text { Body scan meditation } \\
\text { Introduction about self-compassion } \\
\text { Self-compassion touch }\end{array}$ \\
\hline 2 & $\begin{array}{l}\text { Add simple core } \\
\text { strength } \\
\text { exercise }\end{array}$ & $\begin{array}{l}\text { Hallowing } \\
\text { training }\left(4^{*} 15 \mathrm{~s}\right) \\
\text { Hip bridge } \\
\quad\left(4^{*} 15 \mathrm{~s}\right) \\
\text { Simplified bird } \\
\text { dog }\left(4^{*} 30 \mathrm{~s}\right) \\
\text { Half plank } \\
\left(4^{*} 30 \mathrm{~s}\right)\end{array}$ & $\begin{array}{l}\text { Experience } \\
\text { compassion }\end{array}$ & $\begin{array}{l}\text { The relationship between the three emotional systems } \\
\text { (threat system, drive-reward system, soothing system) } \\
\text { and self-compassion; } \\
\text { Affectionate breathing; } \\
\text { Compassionate image }\end{array}$ \\
\hline 3 & $\begin{array}{l}\text { Add intensive } \\
\text { core strength } \\
\text { exercise }\end{array}$ & $\begin{array}{l}\text { Inverted bicycle } \\
\text { ride }\left(4^{*} 15 s\right) \\
\text { Hip-single leg } \\
\text { support }\left(4^{*} 15 s\right) \\
\text { Bird dog }\left(4^{*} 30 s\right) \\
\text { Dead bug }\left(20^{*} 5 s\right)\end{array}$ & $\begin{array}{l}\text { Self- } \\
\text { compassion } \\
\text { under } \\
\text { pressure }\end{array}$ & $\begin{array}{l}\text { Discussion about home practice; } \\
\text { Inner child; } \\
\text { Self-compassion writing }\end{array}$ \\
\hline 4 & Summary & $\begin{array}{l}\text { Develop } \\
\text { personalized } \\
\text { exercise } \\
\text { programs }\end{array}$ & On the road & $\begin{array}{l}\text { Brief loving-kindness meditation; } \\
\text { Self-compassion phrases; } \\
\text { Review and share; } \\
\text { Wishing bottle }\end{array}$ \\
\hline
\end{tabular}

16-weeks follow-up (primary endpoint). Baseline data collection included demographic and clinical characteristics, such as gender, age, work status, height, weight, education, treatment history, and medical history. Participants self-assessed their outcomes by filling out electronic questionnaires.

\section{Outcome Measurements}

\section{Primary Outcomes}

The primary outcomes for the study are disability associated with low back pain and pain intensity. Back pain disability was assessed using the RMDQ on a scale of 0-24, where higher scores indicate greater functional limitation. The Simplified Chinese Version of 
RMDQ has demonstrated good reliability and validity, internal consistency (Cronbach's alpha) was 0.874 , and intraclass coefficient of correlation (ICC) was 0.952 [31].

Pain intensity was assessed with the Numeric Rating Scale (NRS), which measures mean pain intensity during the last week on a scale of $0-10$, where higher scores indicate greater pain intensity [32]. We selected three NRS types: average NRS (average pain intensity over the last week), current NRS (current pain intensity), and most severe NRS (most severe pain intensity over the last week) [33].

\section{Secondary Outcomes}

The secondary outcomes were measured using questionnaires involving psychological status such as anxiety, depression, pain catastrophizing, and self-efficiency.

Anxiety was measured with the seven-item Generalized Anxiety Disorder scale (GAD-7; range, 0-21, where higher scores indicate greater severity). The GAD-7 has good reliability, validity, and measurement invariance among Chinese medical postgraduate students (Cronbach's alpha was 0.93 and the ICC ranged from 0.71 to 0.87 ) [34].

Depressive symptoms were assessed with the Patient Health Questionnaire-9 (PHQ-9; range, 0-27, where higher scores indicate greater severity). In the general Chinese population, the Chinese version of the PHQ-9 is a valid and efficient tool for screening depression (Cronbach's alpha was 0.86 and the ICC was 0.86) [35].

Pain catastrophizing was assessed with the Pain Catastrophizing Scale (PCS). The PCS consists of 13 items, and each item is answered with a numeric value between 0 and 4 ; 0 corresponding to "not at all", and four corresponded to "all the time". Higher scores indicate a higher level of pain catastrophizing, the Chinese version of the PCS has demonstrated a good reliability and validity (Cronbach's alpha was 0.87 and the ICC was 0.97) [36].

Self-efficiency was assessed with the Pain Self-Efficiency Questionnaire (PSEQ). The PSEQ consists of ten items and assesses the extent to how confident the participant is in performing a range of certain activities using a seven-point
Likert scale, with 0 denoting no confidence at all and 6 denoting complete confidence. A higher total score after adding up the score of each item, indicates stronger confidence in mastering self-efficiency, the simplified Chinese version of PSEQ showed satisfactory psychometric properties in Chinese population with low back pain (Cronbach's alpha was 0.95 and the ICC was 0.91) [37].

\section{Randomization and Allocation}

For the randomization, a simple block randomization process was conceived and implemented by a trial assistant (YJJ). After eligibility was confirmed, every participant was assigned a unique number as an identifier. Sequence generation was achieved using IBM's Statistical Package for Social Sciences (SPSS) Version 22 software, and stratified with a 1:1 allocation random block size of 10 . The randomization list reports a progressive randomization number for randomized participants (from 1 to 20), and a treatment group (intervention or control) was assigned to each participant. The trial assistant (YJJ) who was not involved in the entire treatment procedure generated and maintained the allocation sequence. The principal investigator (ZFM) enrolled and assigned participants to the groups according to their unique numbers. Once allocated, the participant was not allowed to change their groups.

\section{Blinding}

Potential participants were told that they would be randomized to receive one of "two different pain self-management programs". During the intervention, participants only knew the participants in their own treatment group. Each group received treatment at separate times to prevent contact between participants of the two groups. The physiotherapists and psychologists could not be blinded to group allocation due to the study design. 


\section{Statistical Analysis}

We performed statistical analysis according to the intention-to-treat principle. We compared the baseline demographic and clinical characteristics of the groups using Fisher's exact test for categorical variables. For continuous variables, we performed exploratory data analysis and Shapiro-Wilk tests in order to determine the normality of our data distributions first. When the results fit a normal curve, we used an independent $t$ test; when the results did not fit a normal curve, we used a rank-sum test. The feasibility outcomes were reported descriptively and narratively. The primary endpoint of the study is the change in RMDQ and NRS during the 16-week study. Analysis of the primary and secondary continuous outcome variables was carried out using mixed model for repeated measures (MMRM) under the missing-at-random (MAR) assumption. The MMRM model included fixed factors for treatment, visit (weeks 4,16 ; as categorical variable), and treatment-byvisit interaction, and include baseline value as a covariate. An unstructured covariance matrix was used to model the within-subject correlation. Kenward-Roger approximation was used to calculate the denominator degree of freedom. Treatment effects were summarized as the estimated between-group difference in RMDQ and NRS scores at week 16 and the associated 95\% CI. Similar analyses examined the treatment effect for all secondary outcomes. In order to assess the robustness of the primary analysis results by deviating away from the MAR assumption, sensitivity analyses, a pattern mixture model with control-based multiple imputation was performed on the primary endpoints. Specifically, jump to reference model was used. Analyses were performed with SAS software (version 9.3; SAS Institute Inc. Cary, NC).

\section{RESULTS}

\section{Participants}

We screened a total of 94 patients for eligibility, and 40 patients met our eligibility criteria. Of these 40 potential participants, 37 completed the follow-up assessments and were included in our analysis (Fig. 2). Of these 37 participants, 28 $(75.7 \%)$ were female. The mean (SD) age was 35.2 (11.1) years. Participants had relatively high education levels, with 33(89.2\%) having a bachelor's degree or above. Interestingly, we found that no one had ever chosen psychotherapy as the history of therapy. We showed certain characteristics of the participants in Table 2.

After Shapiro-Wilk tests, we found that age, RMDQ, average NRS, current NRS, most severe NRS and PSEQ do not fit a normal distribution, so we used a rank-sum test to perform our comparisons. PCS shows significant statistical significance in the baseline measures. We found no significant differences in the baseline measures of the rest of the outcome scores.

\section{Efficacy}

Figure 3 reports the changes over time within and between the two groups for the primary and secondary outcome measures. Table 3 reports the between-group post-treatment comparisons and the change from baseline for all primary and secondary outcomes. Of all the outcomes, we found only significant intergroup differences in GAD-7 (difference in GAD-7 score at week $16,-2.156[95 \% \mathrm{CI}-4.434$ to $0.122 ; P=0.030])$. The results showed that the intervention group was superior to the control group in improving anxiety.

For all primary outcomes, both groups experienced relief of function and pain after treatment. Although there were no significant differences between groups, we found that participants in the intervention group improved function and pain earlier. Specifically, the RMDQ score changed by -1.771 points $(95 \%$ CI -3.768 to 0.227 ) from baseline to 4 weeks in the control group and by -4.822 points $(95 \%$ CI -6.752 to -2.892 ) in the intervention group (difference between groups, -3.052 [95\% CI -5.836 to -0.267$])$. The RMDQ score changed by -3.328 points $(95 \% \mathrm{CI}-5.252$ to $-1.403)$ from baseline to 16 weeks in the control group and by -5.124 points (95\% CI 


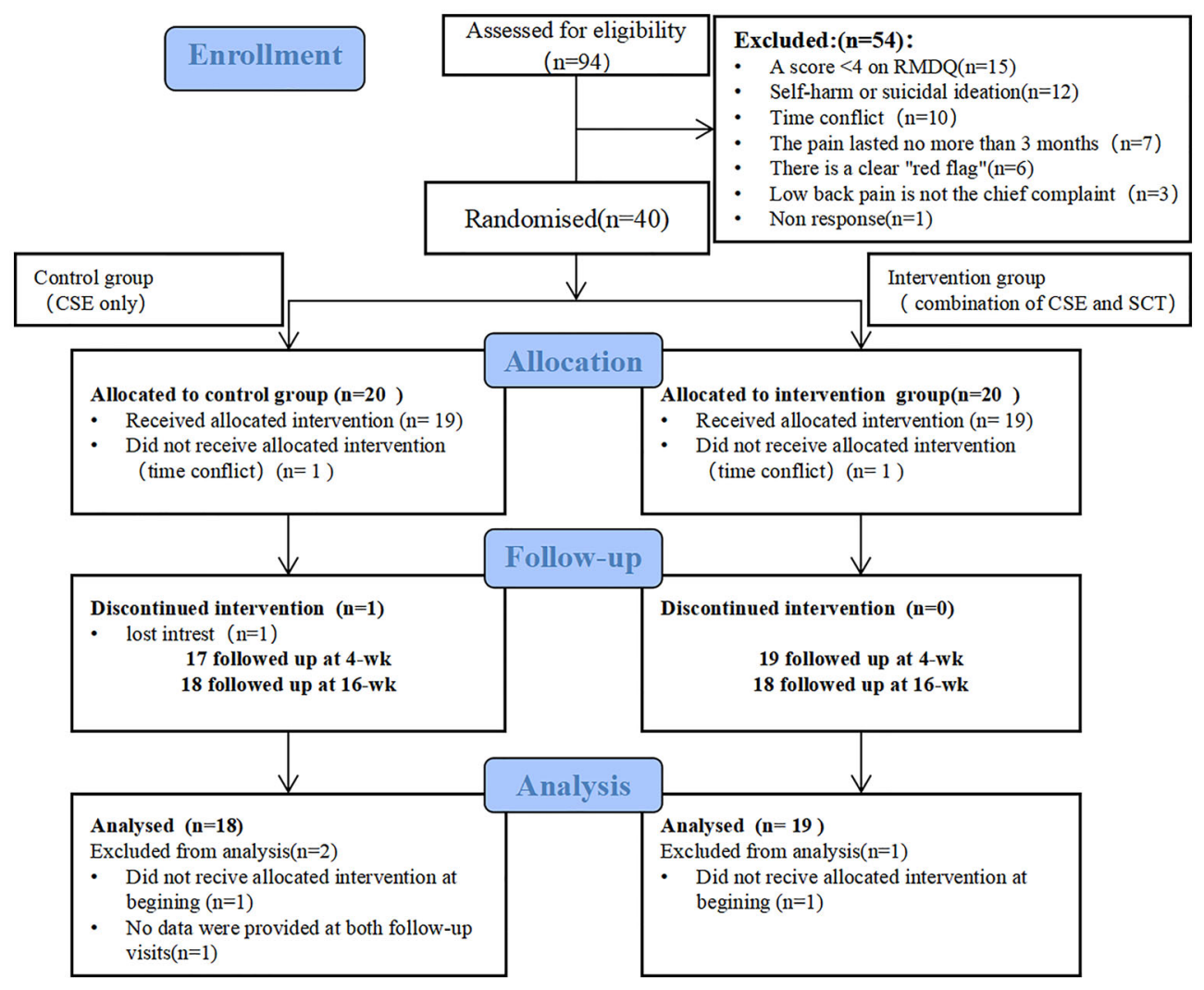

Fig. 2 CONSORT diagram of study participation

-7.014 to -3.233$)$ in the intervention group (difference between groups, - 1.796 [95\% CI 4.501 to 0.909$])$. A similar pattern was found in the NRS scores.

For secondary outcomes, we paid more attention to the patient's psychological status. In addition to the anxiety changes mentioned above, depression scores (PHQ-9) in the intervention group also improved better than those in the control group (see Table 3 and Fig. 3). At the end of treatment, the improvement in PCS in the intervention group was significant (difference in PCS score at week 4, - 6.718 [95\% $\mathrm{CI}-11.872$ to -1.564$])$. We also found significant changes in PCS in the control group $(-6.326$ [95\% CI -11.250 to -1.401$])$ at the 16-week follow-up. As for self-efficiency, there were no apparent differences between the two groups. The sensitivity analysis using the jump to reference model was performed. The results were in agreement with the MMRM analysis.

\section{Sample Size Calculation}

Since this was a pilot study, a sample size calculation was not performed, but the sample size of future study could be calculated based on the results of the pilot study. We found a mean difference of 5.5 for RMDQ with a standard deviation of 4.7 in intervention group, and a mean difference of 3.1 with a standard deviation of 4.8 in control group at 16-week followup. To detect it at 16 weeks with a two-sided significance level (alpha) of 0.05 and power of $80 \%$ with equal allocation to two arms would require 66 patients in each arm of the trial. To allow for $20 \%$ drop out, future study must include at least 166 participants (83 in each group). Calculations were performed with PASS software (version 15). 
Table 2 Baseline characteristics of participants by treatment group

\begin{tabular}{|c|c|c|c|}
\hline & Intervention group $(n=19)$ & Control group $(n=18)$ & $P$ value \\
\hline Age, mean (SD) & $31.5(8.5)$ & $39.2(12.3)$ & 0.066 \\
\hline Female, $n(\%)$ & $14(73.7)$ & $14(77.8)$ & 0.538 \\
\hline BMI, mean (SD) & $20.8(2.1)$ & $22.3(2.8)$ & 0.457 \\
\hline \multicolumn{4}{|l|}{ History of therapy, $n(\%)$} \\
\hline Massage & $8(42.1)$ & $6(33.3)$ & 0.417 \\
\hline Physiotherapy & $8(42.1)$ & $9(50.0)$ & 0.440 \\
\hline Exercise & $6(31.6)$ & $5(27.8)$ & 0.543 \\
\hline Acupuncture & $2(10.5)$ & $4(22.2)$ & 0.303 \\
\hline Drugs & $8(42.1)$ & $7(38.9)$ & 0.554 \\
\hline Traction & $2(10.5)$ & $2(11.1)$ & 0.677 \\
\hline Psychotherapy & $0(0)$ & $0(0)$ & NA \\
\hline Untreated & $5(26.3)$ & $6(33.3)$ & 0.457 \\
\hline \multicolumn{4}{|l|}{ Pain duration, $n(\%)$} \\
\hline 3 Months to 1 year & $6(31.6)$ & $6(33.3)$ & 0.369 \\
\hline 1 Year to 5 years & $10(52.6)$ & $7(38.9)$ & \\
\hline 5 Years to 10 years & $1(5.3)$ & $2(11.1)$ & \\
\hline Over 10 years & $2(10.5)$ & $3(16.7)$ & \\
\hline \multicolumn{4}{|l|}{ Education level, $n(\%)$} \\
\hline Primary school or less & $0(0)$ & $0(0)$ & 0.479 \\
\hline Junior & $0(0)$ & $1(5.6)$ & \\
\hline Senior & $2(10.5)$ & $1(5.6)$ & \\
\hline College or higher & $17(89.5)$ & $16(88.9)$ & \\
\hline \multicolumn{4}{|c|}{ Baseline measures of primary outcome scores } \\
\hline RMDQ & $8.7(3.9)$ & $8.0(3.3)$ & 0.599 \\
\hline Average NRS in the past week & $3.9(1.6)$ & $3.6(1.3)$ & 0.641 \\
\hline Current NRS & $3.7(1.8)$ & $3.3(1.7)$ & 0.538 \\
\hline Most severe NRS in the past week & $4.6(1.9)$ & $4.5(1.3)$ & 0.925 \\
\hline \multicolumn{4}{|c|}{ Baseline measures of secondary outcome scores } \\
\hline PHQ-9 & $5.9(2.5)$ & $4.1(3.0)$ & 0.168 \\
\hline GAD-7 & $4.4(3.4)$ & $3.7(2.4)$ & 0.063 \\
\hline PCS & $20.7(8.3)$ & $23.5(12.7)$ & 0.047 \\
\hline
\end{tabular}


Table 2 continued

\begin{tabular}{llll}
\hline & Intervention group $(\boldsymbol{n}=\mathbf{1 9})$ & Control group $(\boldsymbol{n}=\mathbf{1 8})$ & $\boldsymbol{P}$ value \\
\hline PSEQ & $49.4(8.2)$ & $52.2(9.1)$ & 0.081 \\
\hline
\end{tabular}

The bold value represents a statistical difference

$R M D Q$ Roland and Morris Disability Questionnaire, NRS Numeric Rating Scale, PHQ-9 Patient Health Questionnaire-9, GAD-7 7-item Generalized Anxiety Disorder scale, PCS Pain Catastrophizing Scale, PSEQ Pain Self-Efficiency Questionnaire

A

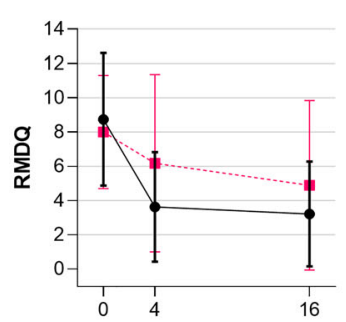

C

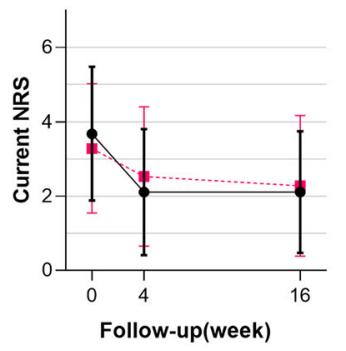

B

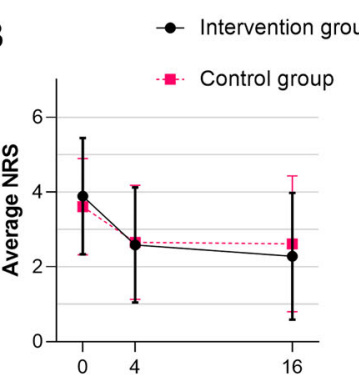

D

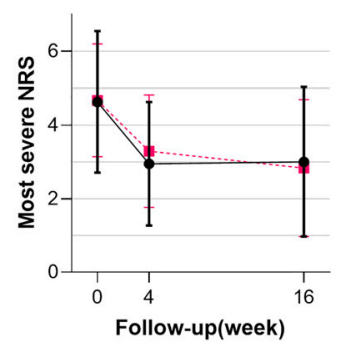

Primary outcomes

Fig. 3 Changes in primary and secondary outcomes. Error bars represent SD. $R M D Q$ Roland and Morris Disability Questionnaire, NRS Numeric Rating Scale, $P H Q-9$ Patient Health Questionnaire-9, GAD-7 7-item

\section{Feasibility}

No adverse effects occurred in the pilot study; $78.9 \%$ (15/19 participants) in the intervention group and $72.2 \%$ (13/18 participants) in the control group attended at least three face-toface group sessions. There was only one dropout in the control group because he had little interest in exercise therapy.

This study is feasible for health care providers and does not take up too many medical resources. In the recruitment stage, the participants were enrolled by electronic

$\mathrm{E}$
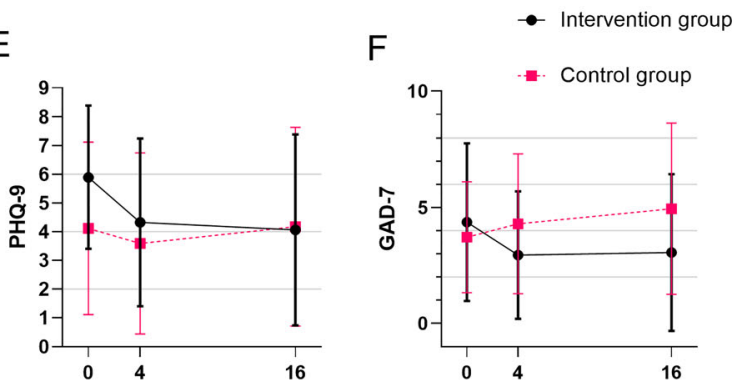

G

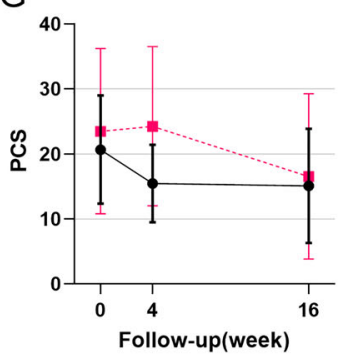

$\mathrm{H}$

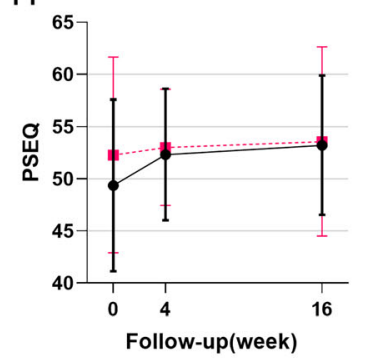

Secondary outcomes

Generalized Anxiety Disorder scale, PCS Pain Catastrophizing Scale, $P S E Q$ Pain Self-Efficiency Questionnaire

questionnaires. Only one investigator worked for 12 weeks to contact 94 interested patients and finally included 40 participants. The whole process was smooth. In the treatment stage, physical therapists and psychotherapists were only required to provide face-to-face guidance once a week, and online guidance at the rest of the time, which would not bring much burden to them. During the data collection stage, the assessors also used the form of electronic questionnaire to reduce a lot of repetitive labor. This study is also feasible for patients' management. The use of AUK and electronic questionnaires 
Table 3 The change from baseline in primary and secondary outcomes (MMRM)

\begin{tabular}{|c|c|c|c|c|}
\hline \multirow{2}{*}{$\begin{array}{l}\text { Follow-up } \\
\text { week }\end{array}$} & \multicolumn{2}{|c|}{ Change from baseline, mean $(95 \% \mathrm{CI})$} & \multirow{2}{*}{$\begin{array}{l}\text { Between-group differences, mean } \\
\text { (95\% CI) } \\
\text { Intervention- Control }\end{array}$} & \multirow{2}{*}{$\begin{array}{l}P \text { val } \\
\text { effec }\end{array}$} \\
\hline & Intervention & Control & & \\
\hline \multicolumn{5}{|c|}{ Roland and Morris Disability Questionnaire (RMDQ) } \\
\hline 4 & $\begin{array}{l}-4.822(-6.752 \\
-2.892)\end{array}$ & $\begin{array}{c}-1.771(-3.768 \\
0.227)\end{array}$ & $-3.052(-5.836,-0.267)$ & 0.0 \\
\hline 16 & $\begin{array}{l}-5.124(-7.014 \\
-3.233)\end{array}$ & $\begin{array}{l}-3.328(-5.252 \\
-1.403)\end{array}$ & $-1.796(-4.501,0.909)$ & \\
\hline
\end{tabular}

Average NRS in the past week

\begin{tabular}{|c|c|c|c|}
\hline 4 & $\begin{array}{l}-1.237(-1.924 \\
-0.551)\end{array}$ & $\begin{array}{l}-0.747(-1.455 \\
-0.039)\end{array}$ & $-0.491(-1.479,0.498)$ \\
\hline 16 & $\begin{array}{l}-1.498(-2.181 \\
-0.815)\end{array}$ & $\begin{array}{l}-1.019(-1.712 \\
-0.326)\end{array}$ & $-0.479(-1.454,0.496)$ \\
\hline
\end{tabular}

Current NRS

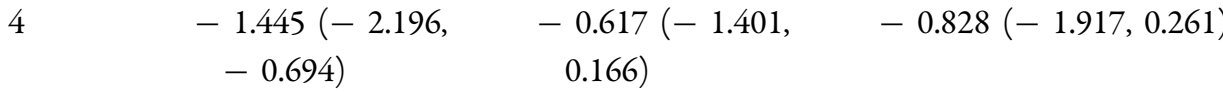

$$
\begin{aligned}
& 16-1.426(-2.136, \quad-1.050(-1.765, \quad-0.375(-1.384,0.634) \\
& -0.715) \quad-0.336)
\end{aligned}
$$

Most severe NRS in the past week

$$
\begin{array}{lllll}
4 & -1.643(-2.385, & -1.094(-1.870, & -0.549(-1.624,0.525) & 0.772 \\
- & 0.900) & -0.317) & \\
& -1.503(-2.269, & -1.776(-2.550, & 0.273(-0.817,1.362) \\
16 & -0.737) & &
\end{array}
$$

Patient Health Questionnaire-9 (PHQ-9)

$$
\begin{array}{cccc}
4 & -1.092(-2.455, & -0.792(-2.227, & -0.300(-2.327,1.728) \\
0.272) & 0.642) & \\
16 & -1.419(-2.936, & -0.399(-1.921, & -1.019(-3.207,1.168) \\
0.099) & 1.123)
\end{array}
$$

0.198

value (group

ffect)

070

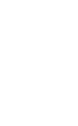


Table 3 continued

\begin{tabular}{|c|c|c|c|c|}
\hline \multirow{2}{*}{$\begin{array}{l}\text { Follow-up } \\
\text { week }\end{array}$} & \multicolumn{2}{|c|}{ Change from baseline, mean $(95 \% \mathrm{CI})$} & \multirow{2}{*}{$\begin{array}{l}\text { Between-group differences, mean } \\
\text { (95\% CI) } \\
\text { Intervention- Control }\end{array}$} & \multirow{2}{*}{$\begin{array}{l}P \text { value (group } \\
\text { effect) }\end{array}$} \\
\hline & Intervention & Control & & \\
\hline 4 & $\begin{array}{l}-5.941(-9.449 \\
-2.433)\end{array}$ & $0.777(-2.948,4.502)$ & $-6.718(-11.872,-1.564)$ & 0.193 \\
\hline 16 & $\begin{array}{l}-6.053(-10.981 \\
-1.124)\end{array}$ & $\begin{array}{l}-6.326(-11.250 \\
-1.401)\end{array}$ & $0.273(-6.713,7.259)$ & \\
\hline \multicolumn{5}{|c|}{ Pain Self-Efficiency Questionnaire (PSEQ) } \\
\hline 4 & $1.943(-0.432,4.318)$ & $2.643(0.146,5.140)$ & $-0.700(-4.168,2.767)$ & 0.867 \\
\hline 16 & $2.785(-1.652,7.221)$ & $2.777(-1.679,7.233)$ & $0.007(-6.293,6.308)$ & \\
\hline
\end{tabular}

The bold value represents a statistical difference

had brought convenience to participants. And the treatment on weekends did not affect their normal work.

\section{DISCUSSION}

\section{Major Findings}

We found a significant improvement in shortterm function and pain at 16 weeks in both groups, and participants in the intervention group experienced faster relief from pain intensity and back disability than those in the control group. The studies have shown that a score change of 3.5 points for the RMDQ was defined as the minimal clinical important difference (MCID) for back pain disability $[38,39]$. In the pilot study, the proportion that meets MCID in RMDQ at 4-week follow-up was $63.2 \%$ (12/19 participants) and 38.9\% (7/18 participants) in the intervention group and the control group, and changed to $68.4 \%(13 / 19$ participants) and $55.6 \%$ (10/18 participants) at 16-week follow-up. This also suggested that more participants in the intervention group were able to relieve symptoms at an earlier time. In terms of psychological status, we found that SCT had a relatively significant effect on alleviating patients' anxiety and depression. The improvement of pain catastrophizing score in the intervention group was better than that in the control group after the treatment, but it improved significantly in the control group at the last follow-up. A systematic review has shown that mobile health technologies had significant effects on pain catastrophizing at short-term follow-up [40]. This may be because the persistence of exercise appears to ease their lower back pain, which in turn alleviates catastrophic thoughts. However, the effect was delayed in the control group compared to the intervention group.

Our study population was slightly younger and better educated, and there was a slightly more pronounced female preponderance. It showed comparable clinical characteristics to another study [41]. Most of them prefer massage, physical therapy, and drugs to relieve lower back pain, although they are not first-line treatments [3]. From the participants' registration information, we found that none of the participants had previously chosen psychotherapy for treatment. This is perhaps unfortunate because patients with NCLBP are in fact prone to anxiety and depression [42, 43]. Moreover, research has shown that there was a significant association between chronic LBP and degree of stress [44]. Interestingly, previous studies have also shown that low back pain symptoms can be alleviated by psychotherapy [45]. Clinical and experimental studies have shown that even a simple psychological manipulation, such as distraction, can have a 
powerful effect on the perception of pain [46]. Strikingly, negative emotions were effectively alleviated in the intervention group of our study, and this may be one reason why SCT works. However, we found no further improvement in function and pain in the intervention group at the last follow-up, which may be related to the fact that participants did not keep doing regular SCT.

From a clinical perspective, these results are encouraging because the exercise prescription and the self-compassion training are both easily reproducible and there is still much room for progress with the rapid development of information technology. Our methods of intervention are effective, economical, and convenient. In the management of NCLBP, imaging, rest, opioids, spinal injections, and surgery are still in high use inappropriately [3]. Our study used a biopsychosocial framework to guide pain management with initial nonpharmacological treatment, including exercise and psychological programs, and this is all in line with international guidelines [47-49]. Furthermore, m-health technology can reduce healthcare burden and costs from both healthcare providers and patients [50]. Therefore, if this study could be promoted, it may bring convenient medical treatment to patients with NCLBP and reduce the workload of the clinicians. It may also give researchers confidence to start similar studies.

\section{Comparison of Results with Other Studies}

Most of the previous studies have focused either on psychotherapy [51] or exercise therapy $[29,52]$. In this study, we combined exercise therapy with psychotherapy based on biopsychosocial models [53]. In addition, we have simplified the treatment process to 4 weeks, using the m-health system, so that participants could receive treatments any time [54]. Participants in the intervention group not only experienced lower back pain relief but also improved their mood. In comparing our results with the study of Cherkin et al. [18], our clinical results are more dramatic and quicker, and it is easier to implement than studies about MBR $[55,56]$.

\section{Limitations and Future Directions}

First, we did not set up a control group receiving SCT alone because, according to our surveys, most patients were skeptical of psychotherapy, and refused to use psychotherapy alone to treat low back pain. In addition, we lacked experience in psychological intervention treatment of NCLBP. We intent to choose the right time to set up this research group in future research. Second, participants all signed up through the scanning electronic questionnaire, and this may lead to selection bias. Such as more highly educated participants and young people would like to sign up, and it is likely to affect the generalizability of the findings. In subsequent studies, the recruitment should be carried out in outpatient communities and other places as well. Third, during the 16 weeks of self-training, the AUK system could provide exercise reminders every day, but due to technical defects, it could not provide SCT reminders, which may have led to the low training frequency of SCT, and we need to improve this in the future research. Finally, except for the behavior performance changes that were assessed, more objective instruments such as fMRI may be needed to investigate underlying mechanisms and changes in brain function in future studies.

\section{CONCLUSIONS}

In conclusion, the pilot study is feasible to deliver. Although there is no significant between-group difference at 16 weeks in both groups for pain and disability, our results indicate that participants in the group of m-healthbased CSE combined with SCT may experience faster relief from pain intensity and back disability than those in the group of m-healthbased CSE alone.

\section{ACKNOWLEDGEMENTS}

The authors thank the participants of the study. 
Funding. This study was supported by the National Natural Science Foundation of China (82172532), the Natural Science Young Scientists Fund of China (82102677), the Natural Science Young Scientists Fund of China (82002375) and the Guangdong Basic and Applied Basic Research Foundation (2019A1515110628). The Rapid Service Fee was funded by the authors.

Editorial Assistance. The authors also thank AiMi Academic Services (www.aimieditor.com) for English language editing and review services, funded by Chuhuai Wang.

Authorship. All named authors meet the International Committee of Medical Journal Editors (ICMJE) criteria for authorship for this article, take responsibility for the integrity of the work as a whole, and have given their approval for this version to be published.

Author Contributions. (I) Conception and design: Fuming Zheng, Weihui Xiao, Yuyin Wang and Chuhuai Wang; (II) Design of CSE: Yiyi Zheng and Shufeng Liu; (III) Design of SCT: Wanting Yang and Weihui Xiao; (IV) Collection and assembly of data: Fuming Zheng and Wenwu Xiao; (V) Data analysis and interpretation: Lichang Chen, Shanshan Zhang, Qiuhua Yu and Zengming Hao; (VI) Trial assistant: Jiajia Yang; (VII) Manuscript writing: Fuming Zheng and Yiyi Zheng.

Disclosures. Fuming Zheng, Yiyi Zheng, Shufeng Liu, Jiajia Yang, Weihui Xiao, Lichang Chen, Wenwu Xiao, Wanting Yang, Shanshan Zhang, Qiuhua Yu, Zengming Hao, Yuyin Wang and Chuhuai Wang have no conflicts of interest to disclose.

Compliance with Ethics Guidelines. This study was performed in accordance with the Helsinki Declaration of 1964 and its later amendments and it was approved by the Institutional Research Ethics Committee of the First Affiliated Hospital, Sun Yat-sen University([2021]079). Written informed consent was obtained from all participants included in the study.
Data Availability. The datasets generated during and/or analyzed during the current study are available from the corresponding author on reasonable request.

Open Access. This article is licensed under a Creative Commons Attribution-NonCommercial 4.0 International License, which permits any non-commercial use, sharing, adaptation, distribution and reproduction in any medium or format, as long as you give appropriate credit to the original author(s) and the source, provide a link to the Creative Commons licence, and indicate if changes were made. The images or other third party material in this article are included in the article's Creative Commons licence, unless indicated otherwise in a credit line to the material. If material is not included in the article's Creative Commons licence and your intended use is not permitted by statutory regulation or exceeds the permitted use, you will need to obtain permission directly from the copyright holder. To view a copy of this licence, visit http://creativecommons.org/licenses/by$\mathrm{nc} / 4.0 /$.

\section{REFERENCES}

1. Maher C, Underwood M, Buchbinder R. Nonspecific low back pain. Lancet. 2017;389(10070): 736-47.

2. Knezevic NN, Candido KD, Vlaeyen J, Van Zundert J, Cohen SP. Low back pain. Lancet. 2021;398(10294):78-92.

3. Foster NE, Anema JR, Cherkin D, Chou R, Cohen SP, Gross DP, Ferreira PH, Fritz JM, Koes BW, Peul W, Turner JA, Maher CG, Buchbinder R, Hartvigsen J, Cherkin D, Foster NE, Maher CG, Underwood M, van Tulder M, Anema JR, Chou R, Cohen SP, Menezes Costa L, Croft P, Ferreira M, Ferreira PH, Fritz JM, Genevay S, Gross DP, Hancock MJ, Hoy D, Karppinen J, Koes BW, Kongsted A, Louw Q, Öberg B, Peul WC, Pransky G, Schoene M, Sieper J, Smeets RJ, Turner JA, Woolf A. Prevention and treatment of low back pain: evidence, challenges, and promising directions. The Lancet. 2018;391(10137):2368-83.

4. Hartvigsen J, Hancock MJ, Kongsted A, Louw Q, Ferreira ML, Genevay S, Hoy D, Karppinen J, Pransky G, Sieper J, Smeets RJ, Underwood M, Buchbinder R, Hartvigsen J, Cherkin D, Foster NE, Maher 
CG, Underwood M, van Tulder M, Anema JR, Chou R, Cohen SP, Menezes Costa L, Croft P, Ferreira M, Ferreira PH, Fritz JM, Genevay S, Gross DP, Hancock MJ, Hoy D, Karppinen J, Koes BW, Kongsted A, Louw Q, Öberg B, Peul WC, Pransky G, Schoene M, Sieper J, Smeets RJ, Turner JA, Woolf A. What low back pain is and why we need to pay attention. The Lancet. 2018;391(10137):2356-67.

5. Finnerup NB. Nonnarcotic methods of pain management. N Engl J Med. 2019;380(25):2440-8.

6. Skelly AC, Chou R, Dettori JR, Turner JA, Friedly JL, Rundell SD, Fu R, Brodt ED, Wasson N, Kantner S, Ferguson A. Noninvasive nonpharmacological treatment for chronic pain: a systematic review update. Rockville: Agency for Healthcare Research and Quality (US); 2020.

7. Kamper SJ, Apeldoorn AT, Chiarotto A, Smeets RJEM, Ostelo RWJG, Guzman J, van Tulder MW. Multidisciplinary biopsychosocial rehabilitation for chronic low back pain: Cochrane systematic review and meta-analysis. BMJ. 2015;350 (Feb 18 5):444.

8. Sanchez RE, Alonso PJ, Munoz FA, Battaglino A, Castaldo M, Cleland JA, Villafane JH. Reliability of sonography measures of the lumbar multifidus and transversus abdominis during static and dynamic activities in subjects with non-specific chronic low back Pain. Diagnostics (Basel). 2021;11(4):632.

9. Naghdi N, Mohseni-Bandpei MA, Taghipour M, Rahmani N. Lumbar multifidus muscle morphology changes in patient with different degrees of lumbar disc herniation: an ultrasonographic study. Medicina (Kaunas). 2021;57(7):699.

10. Kim KH, Cho SH, Goo BO, Baek IH. Differences in transversus abdominis muscle function between chronic low back pain patients and healthy subjects at maximum expiration: measurement with realtime ultrasonography. J Phys Ther Sci. 2013;25(7): 861-3.

11. Saragiotto BT, Maher CG, Yamato TP, Costa LO, Menezes CL, Ostelo RW, Macedo LG. Motor control exercise for chronic non-specific low-back pain. Cochrane Database Syst Rev. 2016;1:D12004.

12. Cashin AG, Booth J, McAuley JH, Jones MD, Hübscher M, Traeger AC, Fried K, Moseley GL. Making exercise count: Considerations for the role of exercise in back pain treatment. Musculoskelet Care. 2021. https://doi.org/10.1002/msc.1597.

13. Du S, Liu W, Cai S, Hu Y, Dong J. The efficacy of e-health in the self-management of chronic low back pain: a meta analysis. Int J Nurs Stud. 2020;106: 103507.
14. Asadzadeh A, Kalankesh LR. A scope of mobile health solutions in COVID-19 pandemics. Inform Med Unlocked. 2021;23: 100558.

15. Hollander JE, Carr BG. Virtually perfect? Telemedicine for Covid-19. N Engl J Med. 2020;382(18): 1679-81.

16. Gould HM, Atkinson JH, Chircop-Rollick T, D'Andrea J, Garfin S, Patel SM, Funk SD, Capparelli EV, Penzien DB, Wallace M, Weickgenanta AL, Slater M, Rutledge T. A randomized placebo-controlled trial of desipramine, cognitive behavioral therapy, and active placebo therapy for low back pain. Pain. 2020;161(6):1341-9.

17. Khan M, Akhter S, Soomro RR, Ali SS. The effectiveness of Cognitive Behavioral Therapy (CBT) with general exercises versus general exercises alone in the management of chronic low back pain. Pak J Pharm. Sci. 2014;27(4 Suppl):1113-6.

18. Cherkin DC, Sherman KJ, Balderson BH, Cook AJ, Anderson ML, Hawkes RJ, Hansen KE, Turner JA. Effect of mindfulness-based stress reduction vs cognitive behavioral therapy or usual care on back pain and functional limitations in adults with chronic low back pain: a randomized clinical trial. JAMA. 2016;315(12):1240-9.

19. Berry MP, Lutz J, Schuman-Olivier Z, Germer C, Pollak S, Edwards RR, Gardiner P, Desbordes G, Napadow V. Brief self-compassion training alters neural responses to evoked pain for chronic low back pain: a pilot study. Pain Med. 2020;21(10): 2172-85.

20. Lutz J, Berry MP, Napadow V, Germer C, Pollak S, Gardiner P, Edwards RR, Desbordes G, SchumanOlivier Z. Neural activations during self-related processing in patients with chronic pain and effects of a brief self-compassion training - a pilot study. Psychiatry Res. 2020;304: 111155.

21. Neff K. Self-compassion: an alternative conceptualization of a healthy attitude toward oneself. Self Identity. 2003;2(2):85-101.

22. Carvalho SA, Gillanders D, Palmeira L, Pinto-Gouveia J, Castilho P. Mindfulness, self-compassion, and depressive symptoms in chronic pain: the role of pain acceptance. J Clin Psychol. 2018;74(12): 2094-106.

23. Torrijos Zarcero M, Mediavilla R, Rodríguez Vega B, Del Río DM, López Álvarez I, Rocamora González C, Palao TÁ. Mindful Self-Compassion program for chronic pain patients: a randomized controlled trial. Eur J Pain. 2021;25(4):930-44. 
24. Sirois FM, Kitner R, Hirsch JK, Kazak AE. Self-compassion, affect, and health-promoting behaviors. Health Psychol. 2015;34(6):661-9.

25. Terry ML, Leary MR, Mehta S, Henderson K. Selfcompassionate reactions to health threats. Pers Soc Psychol Bull. 2013;39(7):911-26.

26. Owen PJ, Miller CT, Mundell NL, Verswijveren S, Tagliaferri SD, Brisby H, Bowe SJ, Belavy DL. Which specific modes of exercise training are most effective for treating low back pain? Network metaanalysis. Br J Sports Med. 2020;54(21):1279-87.

27. Chan E, Hamid M, Nadzalan AM, Hafiz E. Abdominal muscle activation: an EMG study of the Sahrmann five-level core stability test. Hong Kong Physiother J. 2020;40(2):89-97.

28. Eldridge SM, Chan CL, Campbell MJ, Bond CM, Hopewell S, Thabane L, Lancaster GA. CONSORT 2010 statement: extension to randomised pilot and feasibility trials. BMJ. 2016;355:i5239.

29. Zheng Y, Ke S, Lin C, Li X, Liu C, Wu Y, Xin W, Ma $\mathrm{C}, \mathrm{Wu}$ S. Effect of core stability training monitored by rehabilitative ultrasound image and surface electromyogram in local core muscles of healthy people. Pain Res Manag. 2019;2019:9130959.

30. Huang J, Lin K, Fan L, Qiao S, Wang Y. The effects of a self-compassion intervention on future-oriented coping and psychological well-being: a randomized controlled trial in Chinese college students. Mindfulness. 2021;12(6):1451-8.

31. Yi H, Ji X, Wei X, Chen Z, Wang X, Zhu X, Zhang W, Chen J, Zhang D, Li M. Reliability and validity of simplified Chinese version of Roland-Morris questionnaire in evaluating rural and urban patients with low back pain. PLoS One. 2012;7(1): e30807.

32. Herr KA, Spratt K, Mobily PR, Richardson G. Pain intensity assessment in older adults: use of experimental pain to compare psychometric properties and usability of selected pain scales with younger adults. Clin J Pain. 2004;20(4):207-19.

33. Morone NE, Greco CM, Moore CG, Rollman BL, Lane B, Morrow LA, Glynn NW, Weiner DK, Cramer H. A mind-body program for older adults with chronic low back pain: a randomized clinical trial. Deutsche Zeitschrift für Akupunktur. 2017;60(1): 30-1.

34. Zhang C, Wang T, Zeng P, Zhao M, Zhang G, Zhai S, Meng L, Wang Y, Liu D. Reliability, validity, and measurement invariance of the general anxiety disorder scale among Chinese medical university students. Front Psychiatry. 2021;12: 648755.
35. Wang W, Bian Q, Zhao Y, Li X, Wang W, Du J, Zhang G, Zhou Q, Zhao M. Reliability and validity of the Chinese version of the Patient Health Questionnaire (PHQ-9) in the general population. Gen Hosp Psychiatry. 2014;36(5):539-44.

36. Shen B, Wu B, Abdullah TB, Zhan G, Lian Q, Vania AA, Huang L. Translation and validation of Simplified Chinese version of the Pain Catastrophizing Scale in chronic pain patients: education may matter. MOL PAIN. 2018;14:2070408237.

37. Yang Y, Yang M, Bai J, Zhao J, Chen K, Zhou X, Wei $\mathrm{X}, \mathrm{Li}$ M. Validation of simplified Chinese version of the pain self-efficacy questionnaire (SC-PSEQ) and SC-PSEQ-2 for patients with nonspecific low back pain in Mainland China. Spine (Philadelphia $\mathrm{Pa}$ 1976). 2019;44(20):E1219-26.

38. Ostelo RW, de Vet HC. Clinically important outcomes in low back pain. Best Pract Res Clin Rheumatol. 2005;19(4):593-607.

39. Maughan EF, Lewis JS. Outcome measures in chronic low back pain. Eur Spine J. 2010;19(9): 1484-94.

40. Moman RN, Dvorkin J, Pollard EM, Wanderman R, Murad MH, Warner DO, Hooten WM. A systematic review and meta-analysis of unguided electronic and mobile health technologies for chronic painIs it time to start prescribing electronic health applications? Pain Med (Malden, Mass). 2019;20(11):2238-55.

41. Toelle TR, Utpadel-Fischler DA, Haas KK, Priebe JA. App-based multidisciplinary back pain treatment versus combined physiotherapy plus online education: a randomized controlled trial. NPJ Digit Med. 2019;2:34.

42. Adilay U, Guclu B, Goksel M, Keskil S. The correlation of SCL-90-R anxiety, depression, somatization subscale scores with chronic low back pain. Turk Neurosurg. 2018;28(3):434-8.

43. Calvo Lobo C, Vilar-Fernández JM, Losa-Iglesias ME, López-López D, Rodríguez-Sanz D, PalomoLópez P, Becerro-de B-V. Depression symptoms among older adults with and without subacute low back pain. Rehabil Nurs. 2019;44(1):47-51.

44. Choi S, Nah S, Jang H, Moon JE, Han S. Association between chronic low back pain and degree of stress: a nationwide cross-sectional study. Sci Rep-UK. 2021;11(1):14549.

45. Luiggi-Hernandez JG, Woo J, Hamm M, Greco CM, Weiner DK, Morone NE. Mindfulness for chronic low back pain: a qualitative analysis. Pain Med. 2018;19(11):2138-45. 
46. Villemure C, Bushnell MC. Cognitive modulation of pain: how do attention and emotion influence pain processing? Amsterdam: Elsevier B.V; 2002. p. 195-9.

47. Stochkendahl MJ, Stochkendahl MJ, Kjaer P, Kjaer P, Hartvigsen J, Hartvigsen J, Kongsted A, Kongsted A, Aaboe J, Aaboe J, Andersen M, Andersen M, Andersen MØ, Andersen MØ, Fournier G, Fournier G, Højgaard B, Højgaard B, Jensen MB, Jensen MB, Jensen LD, Jensen LD, Karbo T, Karbo T, Kirkeskov L, Kirkeskov L, Melbye M, Melbye M, Morsel-Carlsen L, Morsel-Carlsen L, Nordsteen J, Nordsteen J, Palsson TS, Palsson TS, Rasti Z, Rasti Z, Silbye PF, Silbye PF, Steiness MZ, Steiness MZ, Tarp S, Tarp S, Vaagholt M, Vaagholt M. National Clinical Guidelines for non-surgical treatment of patients with recent onset low back pain or lumbar radiculopathy. Eur Spine J. 2018;27(1):60-75.

48. de Campos TF. Low back pain and sciatica in over 16s: assessment and management NICE Guideline [NG59]. J Physiother. 2017;63(2):120.

49. Qaseem A, Wilt TJ, McLean RM, Forciea MA. Noninvasive treatments for acute, subacute, and chronic low back pain: a clinical practice guideline from the American college of physicians. Ann Intern Med. 2017;166(7):514-30.

50. de la Torre-Diez I, Lopez-Coronado M, Vaca C, Aguado JS, de Castro C. Cost-utility and cost-effectiveness studies of telemedicine, electronic, and mobile health systems in the literature: a systematic review. Telemed J E Health. 2015;21(2):81-5.

51. Day MA, Ward LC, Ehde DM, Thorn BE, Burns J, Barnier A, Mattingley JB, Jensen MP. A pilot randomized controlled trial comparing mindfulness meditation, cognitive therapy, and mindfulness-based cognitive therapy for chronic low back pain. Pain Med. 2019;20(11):2134-48.

52. Li X, Liu H, Lin KY, Miao P, Zhang BF, Lu SW, Li L, Wang $\mathrm{CH}$. Effects of different sling settings on electromyographic activities of selected trunk muscles: a preliminary research. Biomed Res Int. 2020;2020:2945952.

53. Casey M, Smart KM, Segurado R, Doody C. Multidisciplinary-based rehabilitation (MBR) compared with active physical interventions for pain and disability in adults with chronic pain: a systematic review and meta-analysis. Clin J Pain. 2020;36(11): 874-86.

54. Chhabra HS, Sharma S, Verma S. Smartphone app in self-management of chronic low back pain: a randomized controlled trial. Eur Spine J. 2018;27(11):2862-74.

55. Ibrahim ME, Weber K, Courvoisier DS, Genevay S. Recovering the capability to work among patients with chronic low Back pain after a four-week, multidisciplinary biopsychosocial rehabilitation program: 18-month follow-up study. BMC Musculoskel Dis. 2019;20(1):1-10.

56. van Erp RMA, Huijnen IPJ, Koke AJA, Abbin FE, den Hollander M, Smeets RJEM. Development and content of the biopsychosocial primary care intervention "Back on Track" for a subgroup of people with chronic low back pain. Physiotherapy. 2017;103(2SI):160-6. 